\title{
The incidence of vesicoureteral reflux in children with urinary tract infections
}

\author{
Gabriel C. Dragan \\ Pediatric Surgery Department, "Dr. Victor Gomoiu" Clinical Hospital for Children, Bucharest, Romania
}

\begin{abstract}
Introduction. Urinary tract infections (UTI) are the most frequent bacterial infection in children. The prevalence of UTIs depend on age and sex and it is higher in boys in the first year of life. After one year of age the prevalence is higher in girls. UTIs can be the first sign of congenital anomalies of the urinary tract and kidney, vesicoureteral reflux (VUR) being the most frequent, especially in children under 2 years of age. Voiding cystouretrography (VCUG) is the "gold standard" in diagnosing and classifying VUR.

Materials and methods. This study is a retrospective analysis of the patients admitted for VCUG in "Grigore Alexandrescu" Emergency Clinical Hospital for Children, Bucharest, between 1st January 2015 and 31st December 2017.

Results. There were 298 VCUGs performed in patients with a history of at least one episode of febrile UTI. 83/298 $(27,9 \%)$ patients were diagnosed with VUR, 36/298 (12.1\%) with bilateral VUR. We observed a negative trend in the incidence of VUR with age $(p<0.05)$. In 296 cases renal bladder ultrasound (RBUS) was available. 179 patients had negative RBUS, $35(19,5 \%)$ of them being diagnosed with VUR, 9 patients $(5 \%)$ with dilating VUR. In patients under 2 years of age the incidence of VUR was $36.4 \%$ (43/118). The incidence of VUR in girls under 2 years of age was $49 \%$ (25/51), with $12 / 51$ girls (23.5\%) having dilating VUR. In boys under 2 years of age the incidence of VUR was $26.9 \%$ (18/67), and $20.9 \%$ (14/67) for dilating VUR.

Conclusions. Although the latest guidelines recommend VCUG only in selected cases, this imaging study remains indispensable in diagnosing VUR. We consider that an individualized approach must be applied in the management of children with a history of UTI.
\end{abstract}

Keywords: urinary tract infection, children, voiding cystouretrography

\section{INTRODUCTION}

Urinary tract infections (UTI) are the most frequent bacterial infection in children; $30 \%$ of patients with a first episode of UTI will have a second UTI in the first 6-12 months $(1,2)$. The prevalence of UTIs depend on age and sex; in the first year of life UTIs are more frequent in boys $(3,7 \%)$ than in girls $(2 \%)$. After the first year of life the incidence is higher in girls $(3 \%)$ than in boys $(1 \%)(1,2)$.

UTIs can be the first sign of congenital anomalies of the urinary tract and kidney (CAKUT), vesicoureteral reflux (VUR) being the most common, especially in the first 2 years of life (3). In the last 4 decades the goal of the management of patients with a first UTI was to preserve kidney function by diagnosing CAKUT that could increase the risk of recurrent UTIs (4). The management of these anomalies included antibiotic prophylaxis and surgical correction of the anomalies if antibiotic prophylaxis did not prevent UTIs (4). Recently, some studies suggested that antibiotic prophylaxis does not offer the expected prevention of UTIs and does not preserve kidney function, thus leading to changes in the management of children with UTI $(5,6,7)$.

In the absence of clinical or biochemical markers for the kidney function, imaging studies are necessary to diagnose CAKUT or renal scarring. Imaging studies include renal bladder ultrasound (RBUS), voiding cystourethrography (VCUG) and renal scan (8). The imaging evaluation of patients with UTI continues to be debated, the moment for performing these different studies being the most controversial. The current trend is to limit the indications of VCUG and renal scan $(4,8,9)$. Exposure to radiations, the risk of catheter-related UTI, psychological stress of children and parents and the cost of these studies are all factors to 
be considered. The purpose of these studies is to diagnose CAKUT, especially VUR; VUR is the most common anomaly that favours UTIs and renal scarring $(3,9,10)$.

VCUG is the "gold standard" in diagnosing and classifying VUR. It offers valuable information on the anatomy of the bladder and the urethra $(11,12)$. VCUG is not routinely performed and the 2011 American Association of Pediatrics (AAP) guidelines recommend VCUG only in patients under 2 years of age with positive RBUS or recurrent or atypical UTI (4). The National Institute for Health and Care Excellence (NICE) 2007 guidelines recommend VCUG in children under 3 years of age with recurrent or atypical UTI and positive RBUS (10). On the other hand, the European Society of Pediatric Urology guidelines recommend VCUG after the first febrile UTI in girls of any age and in boys under 1 year of age; in boys older than 1 VCUG is recommended only in patients with recurrent UTIs (1).

The purpose of this study is to evaluate the prevalence of VUR in children with a history of at least 1 episode of febrile UTI.

\section{MATERIALS AND METHODS}

This study is a retrospective analysis of patients admitted for VCUG in "Grigore Alexandrescu" Emergency Clinical Hospital for Children, Bucharest, between $1^{\text {st }}$ January 2015 and $31^{\text {st }}$ December 2017.

Inclusion criteria were a history of febrile UTI. Patients with a history of VCUG were excluded.

Data were collected from the informatic system of the hospital and were analyzed with Microsoft ${ }^{\circ}$ Excel (ver. 16.15) and IBM ${ }^{\circledR}$ SPSS ${ }^{\circledR}$ Statistics (ver. 25).

\section{RESULTS}

Between $1^{\text {st }}$ January 2015 and $31^{\text {st }}$ December there were 361 VCUGs performed; 298 VCUGs were performed in children with at least one febrile UTI. There were 173/298 (58.1\%) girls. Mean age was 58,1 months, with a minimum of 27 days and a maximum of 17.8 years (Figure 1).

$83 / 298(27.9 \%)$ patients were diagnosed with VUR, 36/298 (12.1\%) with bilateral VUR. There were 119 refluxing renal units, 64 on the left side and

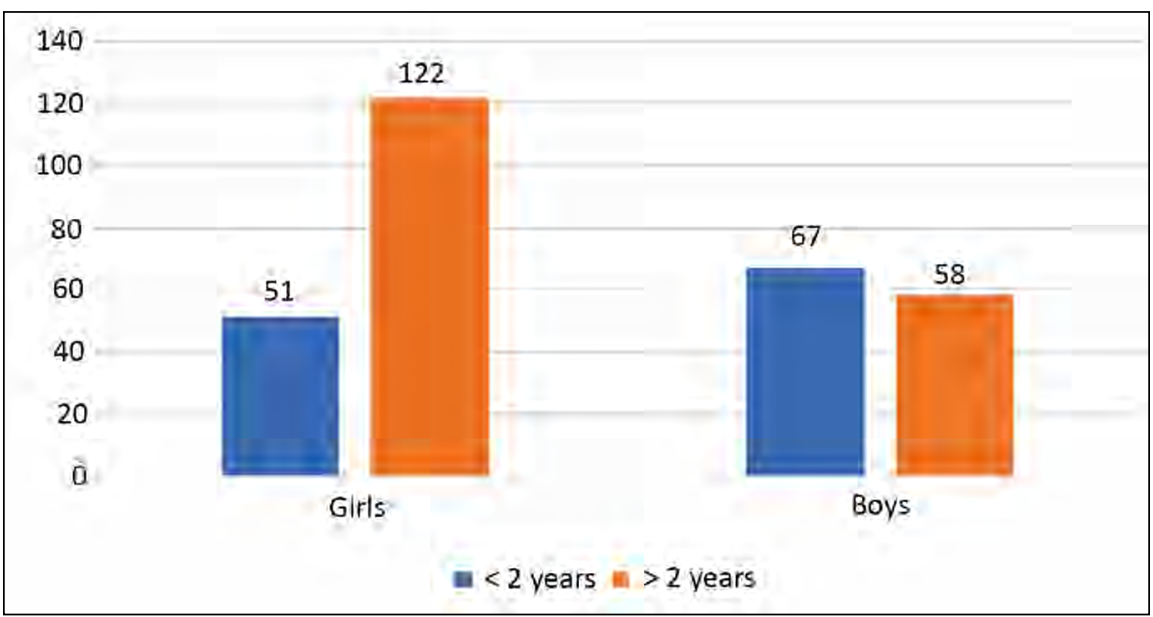

FIGURE 1. Sex distribution depending on age

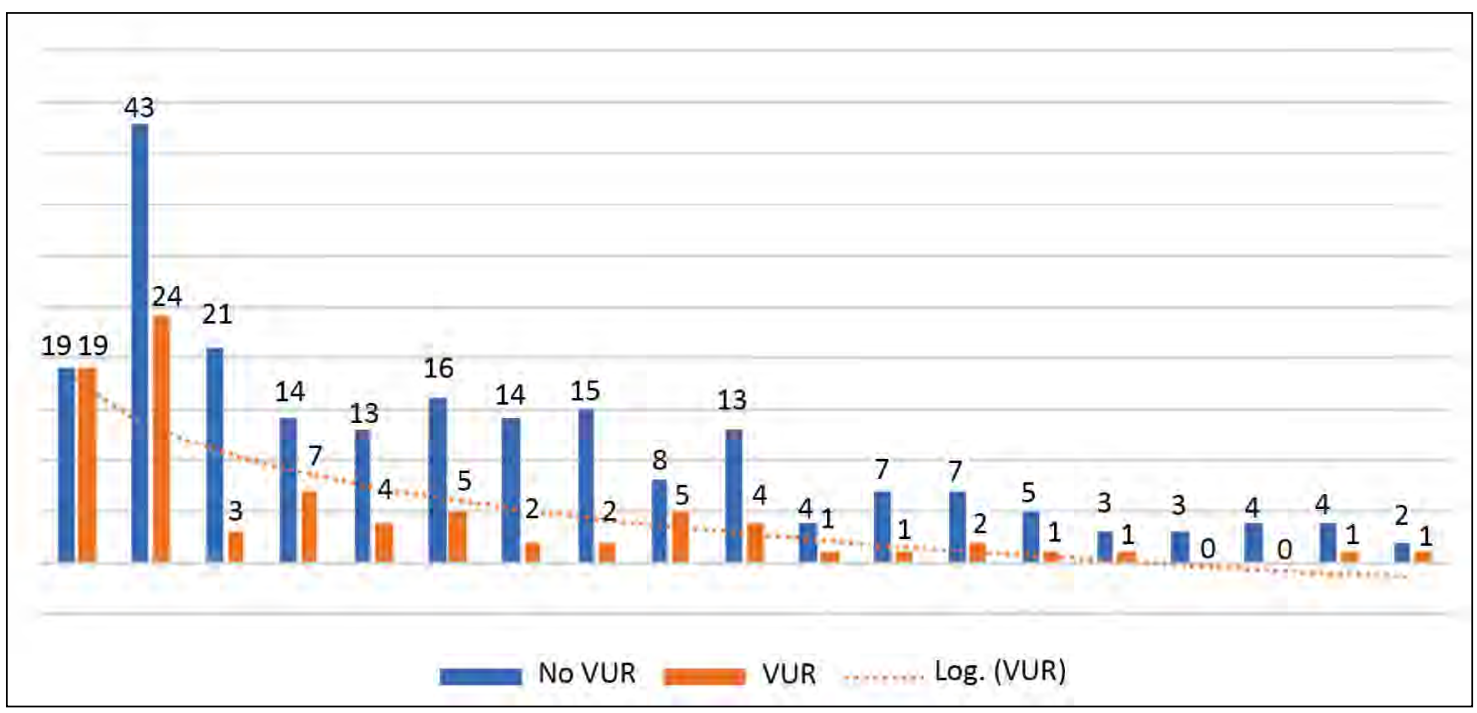


55 on the right side. In 55/119 renal units there was nondilating VUR (grade I-II), while 64/119 renal units had dilating VUR (grade III-V). There was a negative of VUR incidence with age $(p<0.05)$ (Figure 2$)$.

In 296 cases RBUS was available. There were 179 with negative RBUS, 35 (19.5\%) of them being diagnosed with VUR, 9 (5\%) patients with dilating VUR. There were 45 patients with ureterohydronephrosis on RBUS, 26 (57.8\%) of them with VUR, 2 patients with nondilating VUR. 72 patients had only pyelocaliceal dilation on RBUS; 20 (27.8\%) patients were diagnosed with VUR, 14 with dilating VUR (Table 1). 62 patients under 2 years of age had negative RBUS. Of those, 16/62 (25.8\%) had VUR, 4/62 (6.5\%) had dilating VUR.

TABLE 1. RBUS findings depending on VUR grade

\begin{tabular}{|l|c|c|c|c|}
\hline \multirow{2}{*}{} & \multicolumn{4}{|c|}{ RBUS } \\
\cline { 2 - 5 } & Negative & $\begin{array}{c}\text { Uretero- } \\
\text { hydronephrosis }\end{array}$ & $\begin{array}{c}\text { Pyelocalyceal } \\
\text { dilations }\end{array}$ & Total \\
\hline No VUR & 144 & 19 & 52 & 215 \\
\hline $\begin{array}{l}\text { VUR } \\
\text { grade I-II }\end{array}$ & 26 & 2 & 6 & 34 \\
\hline $\begin{array}{l}\text { VUR } \\
\text { grade III-V }\end{array}$ & 9 & 24 & 14 & 47 \\
\hline Total & 179 & 45 & 72 & 296 \\
\hline
\end{tabular}

$51 / 173(29.5 \%)$ of girls had VUR and $25 / 173$ $(14.5 \%)$ had dilating VUR. On the other hand, 32/125 (25.6\%) of boys had VUR and 24/125 (19.2\%) had dilating VUR. These differences are not statistically significant $(\mathrm{p}>0.05)$ (Table 2).

TABLE 2. VUR grade on sex

\begin{tabular}{|l|c|c|c|c|}
\hline & No VUR & VUR grade I-II & VUR grade III-V & Total \\
\hline Girls & 122 & 26 & 25 & 173 \\
\hline Boys & 93 & 8 & 24 & 125 \\
\hline Total & 215 & 34 & 49 & 298 \\
\hline
\end{tabular}

The incidence of VUR in children under 2 years of age was $36,4 \%(43 / 118)$. The incidence of VUR in girls under 2 years of age was $49 \%(25 / 51) ; 12 / 51$ $(23.5 \%)$ had dilating VUR. In boys under 2 years of age the incidence of VUR was $26.9 \%$ (18/67); 14/67 $(20.9 \%)$ had dilating VUR. These differences are statistically significant $(\mathrm{p}<0.05)$ (Table 3$)$.

TABLE 3. VUR grade on sex in children under 2 years of age

\begin{tabular}{|l|c|c|c|c|}
\hline & No VUR & VUR grade I-II & VUR grade III-V & Total \\
\hline Girls & 26 & 13 & 12 & 51 \\
\hline Boys & 49 & 4 & 14 & 67 \\
\hline Total & 75 & 17 & 26 & 118 \\
\hline
\end{tabular}

\section{DISCUSSIONS}

The role of VCUG in children with UTI is to offer information on the anatomy of the lower urinary tract and to diagnose VUR $(11,13)$. The guidelines for imaging studies in these cases are controversial. The 2011 AAP guidelines on the management of children under 2 years of age with febrile UTI recommend VCUG only in recurrent cases of UTI or atypical UTI (non-Escherichia coli, non-favourable outcome with antibiotic treatment, positive RBUS) (1). The 2007 NICE guidelines recommend VCUG in recurrent cases of febrile UTI (10).

The prevalence of VUR in the general pediatric population is unknown, performing VCUG in healthy children being unethical. The prevalence of VUR was estimated to $0.4-1.8 \%(14,15,16)$. The prevalence of VUR is much higher in children with a history of UTI (30-50\%, depending on age) $(15,16)$. In our study the prevalence of VUR was $27.9 \%$ (83/298), with a prevalence of $36.4 \%(43 / 118)$ in children under 2 years of age.

Although boys have a higher risk of VUR $(13,14)$, in our study the prevalence of VUR was higher in girls (29.5\% vs. $25.6 \%$ ), but the prevalence of dilating VUR was higher in boys (14.5\% vs. $19.2 \%)$. These differences are not statistically significant. In children under 2 years of age the prevalence of VUR and dilating VUR is higher in girls ( $49 \%$ vs. $26.9 \%, 23.5 \%$ vs. $20.9 \%$ respectively) $(p<0.05)$. The higher prevalence of VUR in children under 2 years of age is explained by a negative trend of VUR prevalence with age.

RBUS is the first imaging study recommended in febrile UTI, although its value in identifying patients with VUR is controversial, with low sensitivity and specificity $(5,17)$. In our study RBUS was available in 296/298 patients, with $179(60.5 \%)$ negative studies. Our results show that $39.5 \%$ of patients had positive ultrasound. These results are similar to those in other studies; thus, in a study from Sweden $41 \%$ of patients with febrile UTI had a positive ultrasound (17), AlKhateeb et al. reported a positive ultrasound in 59\% of cases (18), and Nelson reported a positive ultrasound in $43.9 \%$ of patients (19).

The prevalence of VUR in patients with negative RBUS was $19.5 \%$ (35/117), with 5\% (9/179) having dilating VUR. In children under 2 years of age, the prevalence of VUR in patients with negative RBUS was $25.8 \%(16 / 62), 4(6.5 \%)$ patients having dilating VUR. The results are similar to those obtained by Rianthavorn, who observed a 7\% VUR prevalence in children under 3 years of age with UTI and negative RBUS (13). Hoberman reported a VUR prevalence of $39 \%$ in 302 cases of febrile UTI in children under 2 years of age, similar to our results (20). On the other hand, Montini reported a lower incidence of VUR $(22 \%)$ in 363 cases of febrile UTI in children under 2 years of age (21). 
The AAP and NICE guidelines recommend lowering the number of VCUG and renal scans, studies that ents as well $(1,10)$. Narchi et al. showed that $31 \%$ of children with VUR and negative RBUS would have been missed if the current NICE guidelines were applied (8). The RIVUR trial (The Randomized Intervention for Children with Vesicoureteral Reflux) showed that most children with VUR grade I-IV have a negative RBUS (7).

Although the management of children with VUR is minimalist, not diagnosing dilating VUR means the absence of therapeutic measures like antibiotic prophylaxis and even surgical intervention $(8,18)$. The purpose of these measures is to prevent recurrent UTIs and renal scars, with potential long-term consequences (arterial hypertension, renal failure) (8).

This study is limited by its retrospective and observational nature. Another limit is the number of pahave a high psychological impact on children and par-

tients, although the data are similar to other studies. In what concerns the correlation between RBUS and VCUG it must be mentioned that RBUS is a subjective, operator-dependent study. In our study there is a heterogeneity in RBUS operator, thus biasing the results.

\section{CONCLUSIONS}

Although the latest guidelines recommend a limitation of VCUG in the management of children with UTI, VCUG remains an indispensable imaging study in diagnosing VUR. RBUS is a noninvasive imaging study, but its efficiency in diagnosing patients at risk to develop renal scars and long-term complications is limited. We consider that an individualized approach depending on patient characteristics must be applied in the management of children with a history of UTI.

Conflict of interest: none declared Financial support: none declared

\section{REFERENCES}

1. Stein R, Dogan HS, Hoebeke P, Kočvara R., Nijman RJM, Radmayr $C$, Tekgül S. Urinary tract infections in children: EAU/ESPU guidelines. European Urology 2015, 67(3), 546-558.

2. Biassoni L. Chippington S. Imaging in Urinary Tract Infections: Current Strategies and New Trends. Seminars in Nuclear Medicine 2008, 38(1), 56-66.

3. Okarska-Napierała M, Wasilewska A, Kuchar E. Urinary tract infection in children: Diagnosis, treatment, imaging - Comparison of current guidelines. Journal of Pediatric Urology 2017, 13(6), 567-573.

4. Guideline CP. Urinary Tract Infection: Clinical Practice Guideline for the Diagnosis and Management of the Initial UTI in Febrile Infants and Children 2 to 24 Months. Pediatrics 2011, 128(3), 595-610.

5. Hannula A, Venhola M, Perhomaa M, Pokka T, Renko M, Uhari M. Imaging the urinary tract in children with urinary tract infection. Acta Paediatrica 2012 (Vol. 100).

6. Simões e Silva AC, Oliveira EA. Atualização da abordagem de infecção do trato urinário na infância. Jornal de Pediatria 2015, 91(6), S2-S10.

7. Nordenström J, Holmdahl G, Brandström P, Sixt R, Stokland E, Sillén U, Sjöström S. The Swedish infant high-grade reflux trial: Study presentation and vesicoureteral reflux outcome. Journal of Pediatric Urology 2017, 13(2), 130-138.

8. Narchi H, Marah M, Khan A. Al-Amri A, Al-Shibli A. Renal tract abnormalities missed in a historical cohort of young children with UTI if the NICE and AAP imaging guidelines were applied. Journal of Pediatric Urology 2015, 11(5), 252.e1-252.e7.

9. Vachvanichsanong P, Dissaneewate P, McNeil E. What Did We Find From Imaging Studies in Childhood Urinary Tract Infection and Which Studies Are Mandatory? Urology 2018, 111, 176-182.

10. Guideline Development Group (2007). Urinary tract infection in children: Diagnosis, treatment and long-term management.

11. Frimberger D, Mercado-Deane MG, McKenna PH. Establishing a standard protocol for the voiding cystourethrography. Pediatrics 2016, 138(5).
12. Lebowitz RL, Olbing H, Parkkulainen KV, Smellie JM, TamminenMöbius TE. International system of radiographic grading of vesicoureteric reflux. Pediatric Radiology 1985, 15(2), 105-109.

13. Rianthavorn P, Tangngamsakul O. Probabilities of Dilating Vesicoureteral Reflux in Children with First Time Simple Febrile Urinary Tract Infection, and Normal Renal and Bladder Ultrasound. Journal of Urology 2016, 196(5), 1541-1545.

14. Hannula A, Venhola M, Renko M, Pokka T, Huttunen NP, Uhari, M. Vesicoureteral reflux in children with suspected and proven urinary tract infection. Pediatric Nephrology 2010, 25(8), 1463-1469.

15. EAU guidelines on vesicoureteral reflux in children. European Urology, 62(3), 534-542.

16. Sargent MA. Opinion. What is the normal prevalence of vesicoureteral reflux? Pediatric Radiology 2000, 30(9), 587-593.

17. Preda I, Jodal U, Sixt R, Stokland E, Hansson S. Value of Ultrasound in Evaluation of Infants With First Urinary Tract Infection. JURO 2010, 183(5), 1984-1988.

18. Alkhateeb NE, Al Azzawi S, Al Tawil NG. Association between UTI and urinary tract abnormalities: A case-control study in Erbil City/lraq. Journal of Pediatric Urology 2014, 10(6), 1165-1169.

19. Nelson C, Chow J, Johnson E, Rosoklija I, Tan W. 651 Test Characteristics and Predictive Value of Ultrasound As a Screening Test for GU Anomalies Among Children Presenting With UTI. Journal of Urology 2013, 189(4S), 2013.

20. Hoberman Alejandro et al. Imaging studies after a first febrile urinary tract infection in young children. New England Journal of Medicine 348.3 (2003): 195-202.

21. Montini $\mathrm{G}$ et al. Value of imaging studies after a first febrile urinary tract infection in young children: Data from Italian renal infection study 1. Pediatrics 2009, 123(2).

22. Hodson E, Wheeler D, Vimalchandra D., Smith G, Craig J. Cochrane review: Interventions for primary vesicoureteric reflux. Evidence-Based Child Health: A Cochrane Review Journal 2008, 3(1), 215-249. 